\title{
Performance of the ARPA-SMR limited-area ensemble prediction system: two flood cases
}

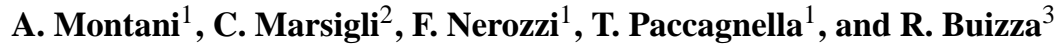 \\ ${ }^{1}$ Regional Meteorological Service ARPA-SMR, Bologna, Italy \\ ${ }^{2}$ Department of Earth Sciences, University of Bologna, Bologna, Italy \\ ${ }^{3}$ European Centre for Medium-Range Weather Forecasts, Reading, UK
}

Received: 26 September 2000 - Revised: 9 March 2001 - Accepted: 10 May 2001

\begin{abstract}
The performance of the ARPA-SMR Limited-area Ensemble Prediction System (LEPS), generated by nesting a limited-area model on selected members of the ECMWF targeted ensemble, is evaluated for two flood events that occurred during September 1992. The predictability of the events is studied for forecast times ranging from 2 to 4 days. The extent to which floods localised in time and space can be forecast at high resolution in probabilistic terms was investigated. Rainfall probability maps generated by both LEPS and ECMWF targeted ensembles are compared for different precipitation thresholds in order to assess the impact of enhanced resolution. At all considered forecast ranges, LEPS performs better, providing a more accurate description of the event with respect to the spatio-temporal location, as well as its intensity. In both flood cases, LEPS probability maps turn out to be a very valuable tool to assist forecasters to issue flood alerts at different forecast ranges. It is also shown that at the shortest forecast range, the deterministic prediction provided by the limited area model, when run in a higherresolution configuration, provides a very accurate rainfall pattern and a good quantitative estimate of the total rainfall deployed in the flooded regions.
\end{abstract}

\section{Introduction}

In recent years, the main weather centres have greatly increased the use of probability forecasts in order to predict the global evolution of the atmospheric flow beyond the short range (namely, from day 2 onward). The National Center for Environmental Prediction, NCEP (Toth and Kalnay, 1993), the Recherche en Prèvision Numèrique, RPN (Houtemaker et al., 1996) and the European Centre for Medium-Range Weather Forecasts, ECMWF (Buizza and Palmer, 1995; Molteni et al., 1996) have developed operational ensemble systems to estimate the predictability of the flow and to de-

Correspondence to: A. Montani

(A.Montani@smr.arpa.emr.it) termine the reliability of the deterministic forecasts for different time-ranges. In fact, ensemble systems enable one to find the probabilities associated with the different evolution scenarios of the atmosphere and their operational use provides an estimate of the day-to-day evolution of the probability distribution function of the atmospheric flow (Molteni et al., 1996). At ECMWF, as in the other centres, computer power resources have greatly increased in the last few years, thereby enabling the operational use of ensembles with more and more members and at higher and higher spatial resolution (at the time of writing, 51 members run at about $120 \mathrm{~km}$ of horizontal resolution with 40 vertical model levels; Buizza et al., 1998). Nevertheless, computer availability is also the main limitation which prevents the running of ensembles at an even higher resolution (Molteni et al., 2001; Marsigli et al., 2001). In fact, while the medium-range predictability of the large-scale flow is usually well captured by the ECMWF ensemble and, in general, by all ensemble systems, the forecast of local events is poorer due to the relatively limited horizontal resolution. This limitation can heavily affect the prediction of local and intense rainfall events, especially over Europe during the warm season (Buizza et al., 1998). In the last few years, much effort has been devoted to the setup of probabilistic forecasts for short time-ranges and over localised regions. Therefore, it has been necessary to further enhance the present-day configuration of ensemble systems.

Among the different approaches used to tackle this problem, a global-model targeted ensemble prediction system (referred to as TEPS) is being developed at ECMWF (Hersbach et al., 2000). In the TEPS experiments, the perturbations that differentiate the initial conditions of the ensemble system are given by linear combinations of singular vectors (SVs) targeted to maximize the 48-hour total energy perturbation over the European area (instead of the extra-tropical northern and southern hemisphere, as in the EPS, the operational Ensemble Prediction System). In the last two years, a joint research group, including the Regional Meteorological Service of Emilia-Romagna ARPA-SMR (in Bologna, Italy), the Royal Netherlands Meteorological Institute and Oslo Univer- 
sity, is carrying out a verification-experimentation program to test the validity of running a TEPS system in order to provide initial and boundary conditions to limited-area models, as well as to improve the probabilistic predictability of rare events (e.g. rainfall exceeding $20 \mathrm{~mm} /$ day) with a global model. A study performed by Hersbach et al. (2000) over 51 case studies suggests the better performance of TEPS over EPS for the short-range (up to 72-96h) prediction of severe events over the European area. Nevertheless, a limitation still remains in the horizontal resolution of TEPS members (the same as EPS), which prevents the spatial-detailed prediction of those fields (e.g. rainfall, surface temperature), where mesoscale and orographic-related processes can play a crucial role.

As an alternative approach, which makes use of global models, Atger (1999) and Ziehmann (2000) propose the "poor man's EPS", generated by joining together forecasts from different weather centres. This approach implicitly considers model uncertainties and provides reliable probabilistic forecasts in the early as well as in the medium range.

Another approach, which takes into consideration uncertainties in the model formulation, but using regional models, is presented by Stensrud et al. (1999a and 1999b). Limitedarea ensembles are generated by perturbing model physics, as well as by generating random initial conditions with the same model. Results are particularly encouraging when ensembles are created by perturbing model physics.

Alternatively, NCEP has recently developed the shortrange ensemble forecasting (SREF) system, based on highresolution versions of NCEP's Eta and Regional Spectral Model. This system is optimised for prediction ranges up to $72 \mathrm{~h}$ and turns out to be very useful for quantitative precipitation predictions (Tracton et al., 1998).

In this study, the attention is focussed on the development of the Limited-area Ensemble Prediction System (LEPS), presented in Molteni et al. (2001) and Marsigli et al. (2001) and developed at ARPA-SMR. In LEPS, a clustering-selection technique is first applied to group ECMWF ensemble members (with a grid scale of approximately $120 \mathrm{~km}$ ) into clusters and a representative member (RM) from each cluster is chosen. Then, each RM is used to provide initial and boundary conditions for the integrations with a high-resolution limited-area model $(20 \mathrm{~km}$ of grid spacing). Hence, the perturbations for the LEPS are of the same scale as the global-model ensemble and there is no account of high-resolution perturbations. In Marsigli et al. (2001), the 5 LEPS integrations are treated as a smallsize high-resolution ensemble over a limited domain and the usual probability products, characteristic of EPS, are prepared for forecast ranges of $120 \mathrm{~h}$. From the results obtained so far, it appears that the high-resolution limited-area integrations have a greater spatial detail in the precipitation patterns and they are capable of predicting, a few days ahead, the occurrence of intense precipitation over localised regions, thereby enabling the issue of an early flood alert. LEPS gives higher probabilities of heavy precipitation than EPS, and the verification carried out against observed values confirms the high accuracy of LEPS predictions of rainfall.

The task attempted in this paper is the combination of the benefits gained by using TEPS instead of EPS to drive LEPS high-resolution members, as well as the investigation of shorter forecast ranges when the differences in either the boundary or the initial conditions associated with the limitedarea model can contribute to the enhancement of the spread obtained by the LEPS integrations. This work investigates the extent to which the configuration TEPS-LEPS can provide information about the possibility of flood occurrence at different time ranges, thereby assisting the forecaster in the confirmation or dismissal of flood alerts. The 4-day, 3-day and 2-day predictability of two flood events that occurred during September 1992 is studied. More precisely, this work investigates the assistance provided to a forecaster by probability products for the different forecast ranges. Once high probabilities of flood occurrence have been predicted, a "higher-resolution" run of the limited-area model will also be performed in order to enhance the spatial detail of the regions affected by the event and to have a more accurate quantitative estimate of the amount of expected rainfall.

The paper is organised as follows: Sect. 2 reviews the methodology followed in the TEPS-LEPS configuration and Sect. 3 presents a brief synoptic description of the case studies. The experimental setup is described in Sect. 4, while the results from TEPS and LEPS integrations are presented in Sects. 5 and 6. Finally, the conclusions are drawn in Sect. 7.

\section{Methodology}

As described by Hersbach et al. (2000), TEPS consists of 51 integrations of the ECMWF operational global model, run at the resolution $T_{L} 159 \mathrm{~L} 40$ (corresponding to about $120 \mathrm{~km}$ in the horizontal with 40 vertical levels). One integration (control) is initialised with the unperturbed analysis; in all the others, the analyses are perturbed in 50 different ways by adding/subtracting properly scaled and targeted initial perturbations (SVs optimized to maximize the growth over the region extending between $35^{\circ} \mathrm{N}-75^{\circ} \mathrm{N}$ and $40^{\circ} \mathrm{W}-30^{\circ} \mathrm{E}$ ). Unlike in Hersbach et al. (2000), where the optimization time interval was set to $72 \mathrm{~h}$, here the perturbation energy is maximised over a shorter time interval $(48 \mathrm{~h})$, since it is thought that the linear assumption under which SVs are calculated is more closely respected in the first two days of evolution.

Concerning the LEPS configuration, the methodology followed to perform the cluster analysis and then to select the representative members is outlined as follows (for more detail, the reader is referred to Molteni et al., 2001).

- All TEPS members are integrated for $t \mathrm{~h}$ (in this work, $t=48,72$ and $96 \mathrm{~h}$, depending on the prediction range of interest).

- At forecast time $t$, the 51 members are grouped into 5 clusters, using as a discriminating variable a combination of four variables at four pressure levels (the two 
horizontal wind components, the geopotential height and the specific humidity at 500, 700, 850 and $925 \mathrm{hPa}$ ).

- All clustering variables are standardised (for each variable, the mean over the clustering area is calculated and subtracted from any grid-point value. Then the result is divided by the standard deviation, so as to obtain a non-dimensional quantity).

- The distances between all TEPS members are computed in a 16-dimensional space ( 4 variables at 4 pressure levels).

- The complete-linkage algorithm (Wilks, 1995) is applied to construct the 5 clusters. The cluster analysis is performed over southern Europe (approximately $53^{\circ} \mathrm{N}-$ $\left.35^{\circ} \mathrm{N} 5^{\circ} \mathrm{W}-25^{\circ} \mathrm{E}\right)$.

- The clusters are numbered in such a way that the control forecast is always in the first cluster.

- One representative member (RM) is selected from each cluster using the same variables that are used to construct the clusters in order to discriminate among members within the same cluster. The RM of a cluster is the member closest to the elements of its own cluster and most distant from those of the other clusters.

Therefore, 5 TEPS members (one RM per cluster) are selected. Each member is representative of a possible evolution scenario highlighted by the model, with the possibility of the occurrence being proportional to the population of the cluster. Once the RMs are determined, they are used as boundary and initial conditions for the integration with the limited-area model that is run for $t \mathrm{~h}$ every time. This produces a 5-member high-resolution ensemble over a limitedarea (hence, LEPS) with a small set of evolution scenarios at a high resolution. Hence, it is possible to construct those probability products (e.g. probability maps for rainfall, temperature and winds exceeding particular thresholds) on the basis of the information provided only by the limited-area integrations. As explained in Molteni et al. (2001), the decision to choose a limited-area ensemble with a 5-member population is driven by the need to keep a sufficient number of different evolution scenarios, as well as by computer power constraints, since it would be very expensive to operationally run a more populated LEPS with the present computer facilities at ARPA-SMR. Nevertheless, the configuration presented in this paper for the TEPS-LEPS system is a suitable compromise among the different needs and could be well implemented on an operational basis.

The limited-area model used to construct the LEPS is the Limited-Area Model BOlogna (LAMBO), operational at ARPA-SMR since 1993. LAMBO, based on a version of the NCEP Eta Model, has a horizontal resolution of $20 \mathrm{~km}$ with 32 vertical levels and it is operationally run twice a day for 72 and $84 \mathrm{~h}$ (nested on ECMWF high-resolution deterministic forecasts of 00:00 and 12:00 UTC, respectively). Its domain covers the Italian peninsula and the Alpine region $\left(1^{\circ} \mathrm{E}-25^{\circ} \mathrm{E}, 36^{\circ} \mathrm{N}-50^{\circ} \mathrm{N}\right)$. For a more detailed description of LAMBO, the reader is referred to Janjic (1990) and Marsigli et al. (2001).

\section{Case study descriptions}

The case studies investigated in this paper deal with two flood events which took place over southern France and northwestern Italy towards the end of September 1992 (Vaisonla-Romaine and Genova flood, respectively). During this period, characterised by highly unstable conditions in the atmospheric flow, mesoscale convective systems developed which affected the southern side of the Alps and caused heavy precipitation events over that region.

\subsection{Vaison-la-Romaine flood}

At 12:00 UTC on 21 September 1992, the mean sea level pressure pattern over western Europe (not shown) was characterised by the Azores' high migration southeastwards; at the same time, another surface low that was centered off the western coast of France was moving eastwards. During the afternoon of 21 September, a cold front reached the French Atlantic coast, and mesoscale convective systems developed ahead of the front (not shown). A low pressure system, deepening over the French Mediterranean coast, was associated with the steady flow of warm, moist air from the southwest. The surface flow, enhanced by the mountains' channelling effect, was characterised by an intense, low-level jet stream in the Gulf of Lion (Senesi et. al., 1996). On 22 September, the axis of the trough tilted and mesoscale convective systems started to develop to the north of the French Mediterranean coast. Intense precipitation was recorded over many locations of this region, with rainfall rates of about $200 \mathrm{~mm}$ in a few hours. In the early hours of 23 September, the low-level circulation was dominated by a $700 \mathrm{hPa}$ geopotential height trough at about $43^{\circ} \mathrm{N} 6^{\circ} \mathrm{E}$ (top left panel of Fig. 1). The village of Vaison-la-Romaine (at about $44^{\circ} \mathrm{N} 5^{\circ} \mathrm{E}$ ) suffered the heaviest precipitation, with maxima of about $300 \mathrm{~mm}$ in $24 \mathrm{~h}$ observed during 23 September (this case study is referred to as the "Vaison case" in the remaining part of this work). Secondary rainfall maxima were also recorded about $100 \mathrm{~km}$ to the northwest of the village, as well as over northwestern Italy (bottom left panel of Fig. 1). Precipitation peaks of about $250 \mathrm{~mm}$ were observed close to the town of Savona, at about $44.3^{\circ} \mathrm{N} 8.4^{\circ} \mathrm{E}$ (not shown).

\subsection{Genova flood}

The synoptic charts (not shown) relative to 12:00 UTC on 26 September 1992 indicated, at both 500 and $700 \mathrm{hPa}$, an intense southwesterly flow blowing over the western Mediterranean. In the following hours, the area affected by this warm and moist flow was located more and more to the east, while an upper-level minimum was placed over Iberia at 00:00 UTC on 27 September. At this time, a surface low was evident to the northwest of the Balearic Islands, at about 

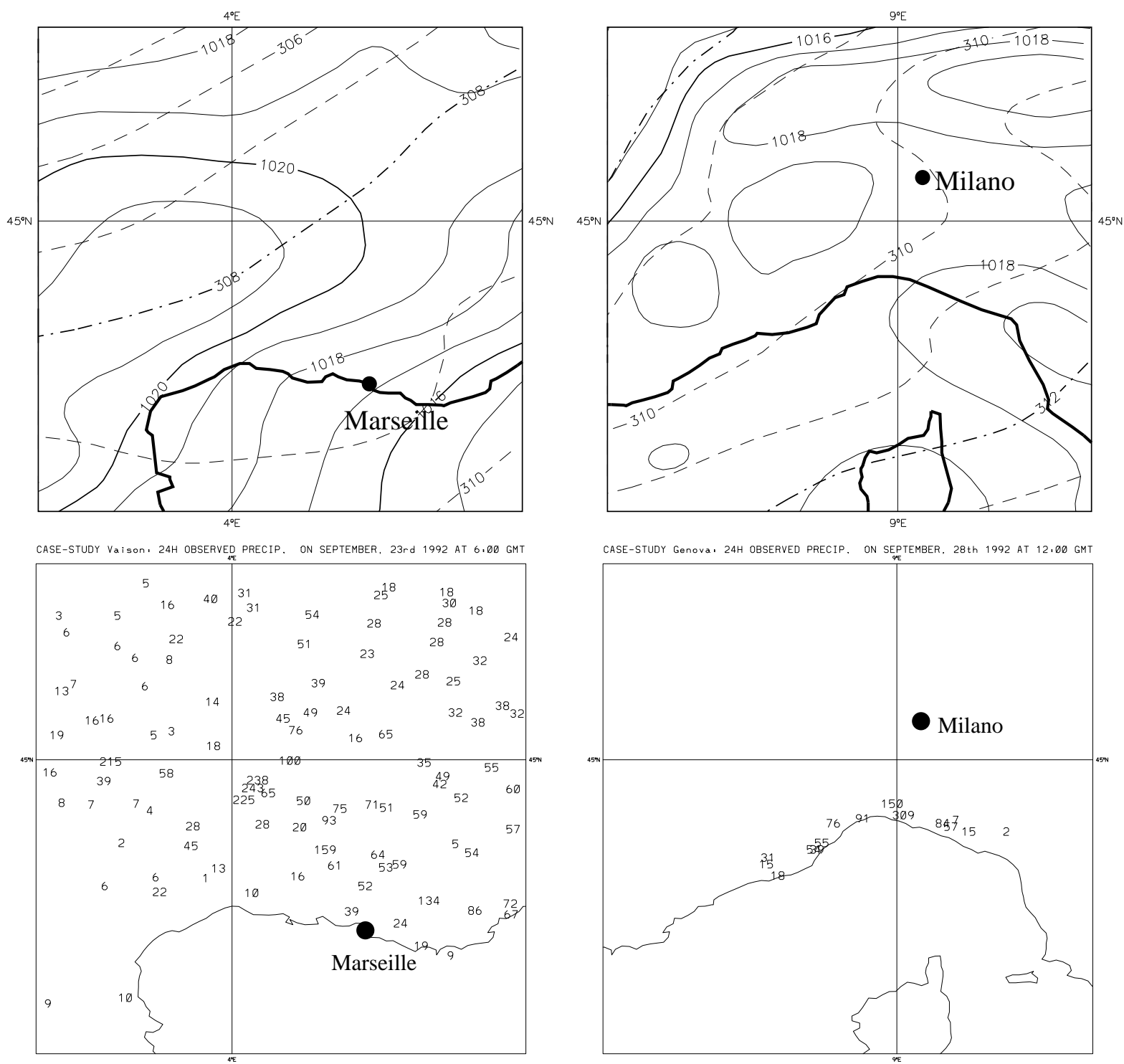

Fig. 1. Left column panels: mean sea level pressure (solid contours) and $700 \mathrm{hPa}$ geopotential height (dashed contours) analyses valid at 06:00 UTC on 23 September 1992 (top left panel) and cumulated rainfall (in mm) observed over the $24 \mathrm{~h}$ period ending at the same time (bottom left panel) for the Vaison case. Right column panels: the same as before, but valid at 12:00 UTC on 28 September 1992 for the Genova case. Contour intervals: $1 \mathrm{hPa}$ and $1 \mathrm{dam}$. Observations from the data sets of the Mesoscale Alpine Project (Vaison case) and from the Centro di ricerca In Monitoraggio Ambientale (Genova case). In the bottom row panels, only a few station data are plotted for clarity purposes.

$42^{\circ} \mathrm{N} 2^{\circ} \mathrm{E}$. In the following hours, both the upper-level minimum and the surface cyclone traveled eastwards, a mean sea level minimum of $1014 \mathrm{hPa}$ was evident over the Gulf of Genova at 00:00 UTC on 28 September. During the first hours of this day, the south, southwesterly flow impacting the Liguria coast (northwestern Italy) was intense, as shown in the top right panel of Fig. 1. Due to the orographic forcing of the Appenines and the Maritime Alps, intense precipitation was widespread in these areas, as well as along the coast. In fact, during 27 and 28 September, heavy rainfall was observed over the Liguria region, with peaks of intensity close to Genova $\left(44.25^{\circ} \mathrm{N}, 8.51^{\circ} \mathrm{E}\right)$ and to the west of the town. Precipitation rates above $200 \mathrm{~mm} /$ day were recorded over several places along the coast (bottom right panel of Fig. 1), thus causing severe damages, as well as two casualties among the local population.

\section{Experiment configuration}

For both cases, the 4-day, 3-day and 2-day predictability is studied. TEPS and LEPS forecasts are always started and verified at 12:00 UTC. Table 1 reports the results of the cluster analysis performed after 96,72 and $48 \mathrm{~h}$ of integrations 
Table 1. Cluster population for the two experiments: Vaison (rows 3-5, cluster time: 12:00 UTC on 23 September 1992) and Genova (rows 6-8, cluster time: 12:00 UTC on 28 September 1992). The results of the cluster analysis for the 4-day forecast range are reported in rows 3 and 6; for the 3-day range, in rows 4 and 7; for the 2-day range, in rows 5 and 8

\begin{tabular}{cccccc}
\hline $\begin{array}{c}\text { experiment } \\
\text { name }\end{array}$ & clst 1 & clst 2 & clst 3 & clst 4 & clst 5 \\
\hline VLR + 4 & 17 & 7 & 16 & 9 & 2 \\
$\mathrm{VLR}+3$ & 16 & 8 & 14 & 11 & 2 \\
$\mathrm{VLR}+2$ & 25 & 10 & 7 & 6 & 3 \\
\hline $\mathrm{GE}+4$ & 28 & 5 & 5 & 5 & 8 \\
$\mathrm{GE}+3$ & 14 & 6 & 10 & 13 & 8 \\
$\mathrm{GE}+2$ & 29 & 9 & 10 & 2 & 1 \\
\hline
\end{tabular}

for the two case studies. The experiments relative to the Vaison flood start on the 19, 20 and 21 September (denoted by $V L R+4, V L R+3$ and $V L R+2$, respectively) and are verified on the 23 September, while the experiments run for the Genova case start on the 24, 25 and 26 September $(G E+4$, $G E+3$ and $G E+2)$ and are all verified on 28 September.

The information provided by TEPS and LEPS products is compared for the different prediction ranges, with particular attention to the quantitative prediction of rainfall. Concerning the ECMWF products, the probability maps are obtained in two different ways:

- by considering all 51 global-model integrations (as in Molteni et al., 1996); hence, the maps are constructed in the traditional way ("51-member TEPS");

- by considering only the $5 \mathrm{RMs}$; the maps are generated by weighting each RM integration according to the cluster population ("5-member TEPS").

On the other hand, LEPS probability maps can be generated by either weighting or not weighting each of the 5 LAMBO integrations according to the population of the cluster in which the RM was selected. Although Marsigli et al. (2001) found a relatively low sensitivity of the LEPS results to the weighting procedure, we chose to weight each LAMBO integration. Weighting should favour the transfer of information about the atmospheric flow predictability from the global TEPS to the LEPS. Two precipitation events have been compared, specifically "24-hour accumulated precipitation exceeding 20 and $50 \mathrm{~mm}$ ". For reason of brevity, the Vaison case is described in greater detail, while the Genova flood is presented in a more cursory way.
Table 2. Vaison flood: cluster population versus Z700 root-meansquare forecast error (in $\mathrm{m}$ and averaged over the clustering area) for the RMs of the 5 clusters and for the different forecast ranges

\begin{tabular}{ccc}
\hline experiment name & cluster population & Z700 rms error \\
\hline & 17 & 19 \\
VLR +4 & 7 & 47 \\
& 16 & 18 \\
& 9 & 26 \\
& 2 & 39 \\
\hline & 16 & 29 \\
VLR +3 & 8 & 38 \\
& 14 & 24 \\
& 11 & 30 \\
& 2 & 32 \\
\hline & 25 & 22 \\
VLR +2 & 10 & 21 \\
& 7 & 19 \\
& 6 & 15 \\
\hline
\end{tabular}

\section{Vaison case}

\subsection{Four-day forecast}

The top row panels of Fig. 2 report the TEPS probability maps (for rainfall exceeding $20 \mathrm{~mm} /$ day) generated in the above described configurations. By comparing the forecasts with the observed rainfall values of Fig. 1 (bottom left panel), one notices that the performance is quite poor for the "51member TEPS", as well as for the "5-member TEPS". In both cases, the 4-day forecasts indicate a chance of rain above $20 \mathrm{~mm} /$ day in Piedmont, on the Italian side of the Alps, while very little precipitation is expected in the region of Vaison. The $10 \%$ contour covers the region of Vaison only in the "5member TEPS" probability map (top right panel), although the differences between the two configurations are almost negligible at other thresholds (not shown). At the $50 \mathrm{~mm} /$ day threshold, the probability is below $10 \%$ in both cases (and the panel is not shown). The misplacement of the region affected by heavy rain is due to, among other factors, the wrong positioning of a $700 \mathrm{hPa}$ trough (not shown) that is located too far to the east in almost all the TEPS forecasts when compared to the analysis. According to many ECMWF forecasts, the system seems to move very quickly and to already have cleared the French area by 23 September.

When LEPS integrations are considered, the situation is slightly better, but far from satisfactory; most of the errors present in the global forecasts can be found again in LAMBO integrations. The rainfall pattern is more detailed and the probabilities are higher, but the highest peaks of precipitation are still located over northern Italy, rather than southern France. In the LEPS forecasts, there is a $16 \%$ probability of the rainfall rate exceeding $20 \mathrm{~mm} /$ day in the vicin- 

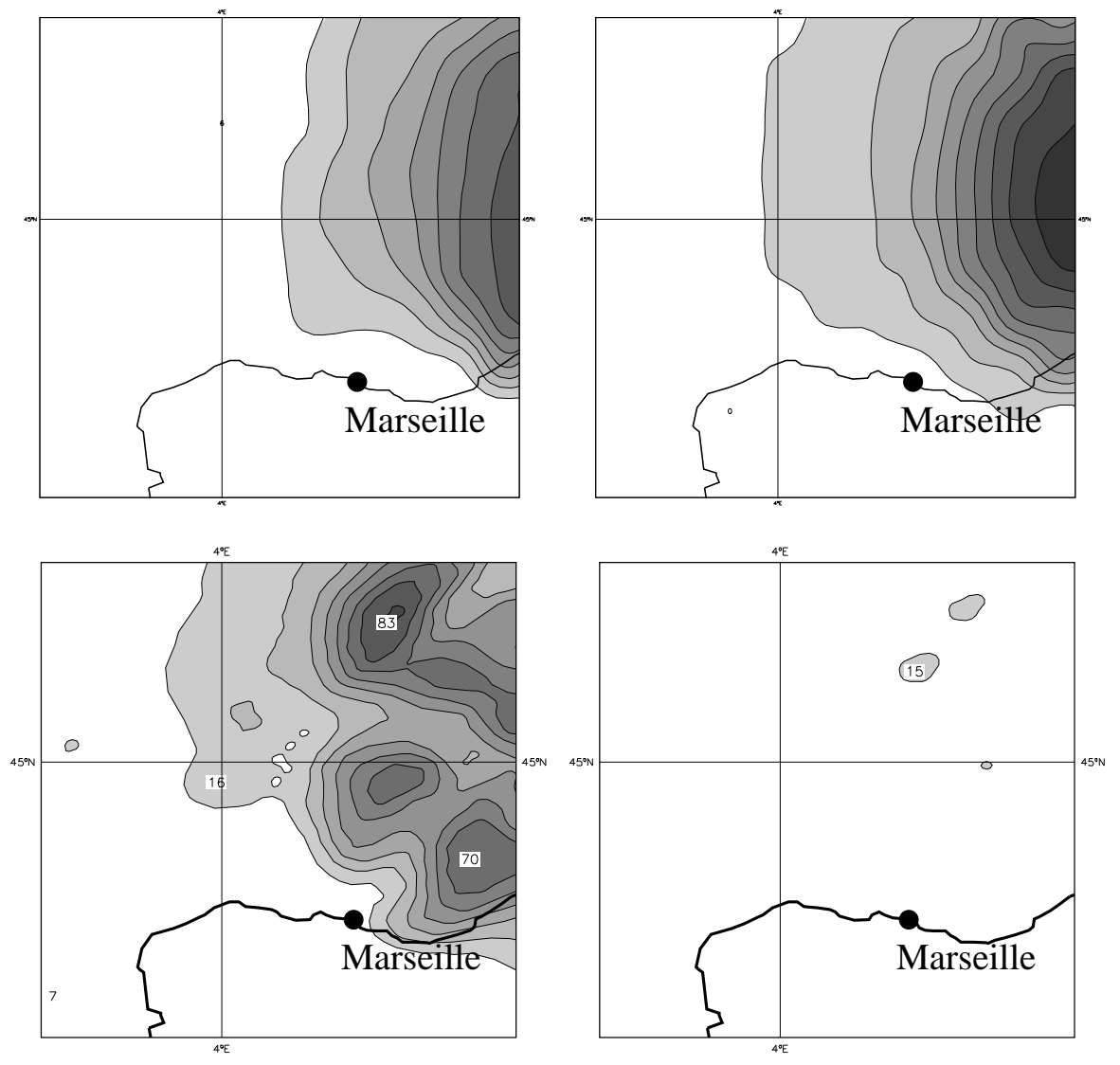

Fig. 2. Vaison flood. 4-day predictions: 51-member and 5-member TEPS probability maps for rainfall exceeding $20 \mathrm{~mm} /$ day (top left and top right panels, respectively) and the LEPS probability maps for rainfall exceeding 20 and $50 \mathrm{~mm} /$ day (bottom left and bottom right panels, respectively). All maps are valid at 6:00 UTC on 23 September 1992 (cumulated between forecasts $t+66 \mathrm{~h}$ and $t+90 \mathrm{~h}$ ). Contours are located at every $10 \%$. ity of the correct location (bottom left panel of Fig. 2), precipitation being also very likely along the northwestern Italian coast. On the other hand, the bottom right panel shows that the probability of rainfall exceeding $50 \mathrm{~mm} /$ day is above $10 \%$ only over northern Italy, a few hundred kms east of the flooded regions (out of the plotted area). It is worth pointing out that 1 out of the 5 LAMBO runs (not shown) nested on the RM of the 5 th cluster (populated by just 2 members) predicts about $40 \mathrm{~mm}$ of rainfall in the correct location. Although the observed amount is much higher (as in Fig. 1), it is encouraging to notice that already 4 days ahead, a heavy rainfall scenario was highlighted by at least one high-resolution forecast. This scenario is depicted as highly unlikely by the cluster analysis; hence, its weight on the final probability map is low. In this case, it would have been more convenient to generate LEPS maps by giving the same weight to each LAMBO integrations in order to increase the relative importance of the more accurate integration. In fact, the probability maps obtained in this further configuration (not shown) indicate a $40 \%$ chance of rainfall exceeding $20 \mathrm{~mm} /$ day in the Vaison area and the signal for a possible flood is clearer than before. Therefore, it looks as if the RM of the least populated cluster is the closest to the verifying analysis in terms of total precipitation.

The results are partly different if the attention is focussed on the circulation field. Table 2 reports, for the experiments relative to the Vaison flood, the root-mean-square (rms) fo- recast errors of each TEPS RM in terms of the geopotential height at $700 \mathrm{hPa}$ (hereafter, Z700) calculated at the final time (and averaged over the cluster analysis domain). For the 4-day range, one notices that the forecast errors are higher for the RMs of the 2 nd and 5th clusters, with the lowest values achieved by the 1 st and 3 rd clusters.

Therefore, the 4-day forecasts by both the TEPS and LEPS systems are quite inaccurate, with the probability of flood occurrence being very low. These results are worse than those obtained by Marsigli et al. (2001), where the 5-day forecast was studied and the EPS instead of the TEPS was used. This is consistent with the trend observed by Hersbach et al. (2000), who found that at this forecast range, the targeted perturbations start to leave the area of interest, thereby worsening the TEPS performance. One also notices that the probability maps generated by the "51-members TEPS" and the "5-member TEPS" are almost identical. Since this result is also confirmed by the other experiments, the maps relative to the latter configuration will not be shown in the next sections and, for the global ensemble, the attention will be focussed on the probability products generated by the " 51 members TEPS".

\subsection{Three-day forecast}

When the 3-day forecast range is considered, the performance of the TEPS and especially the LEPS integrations 

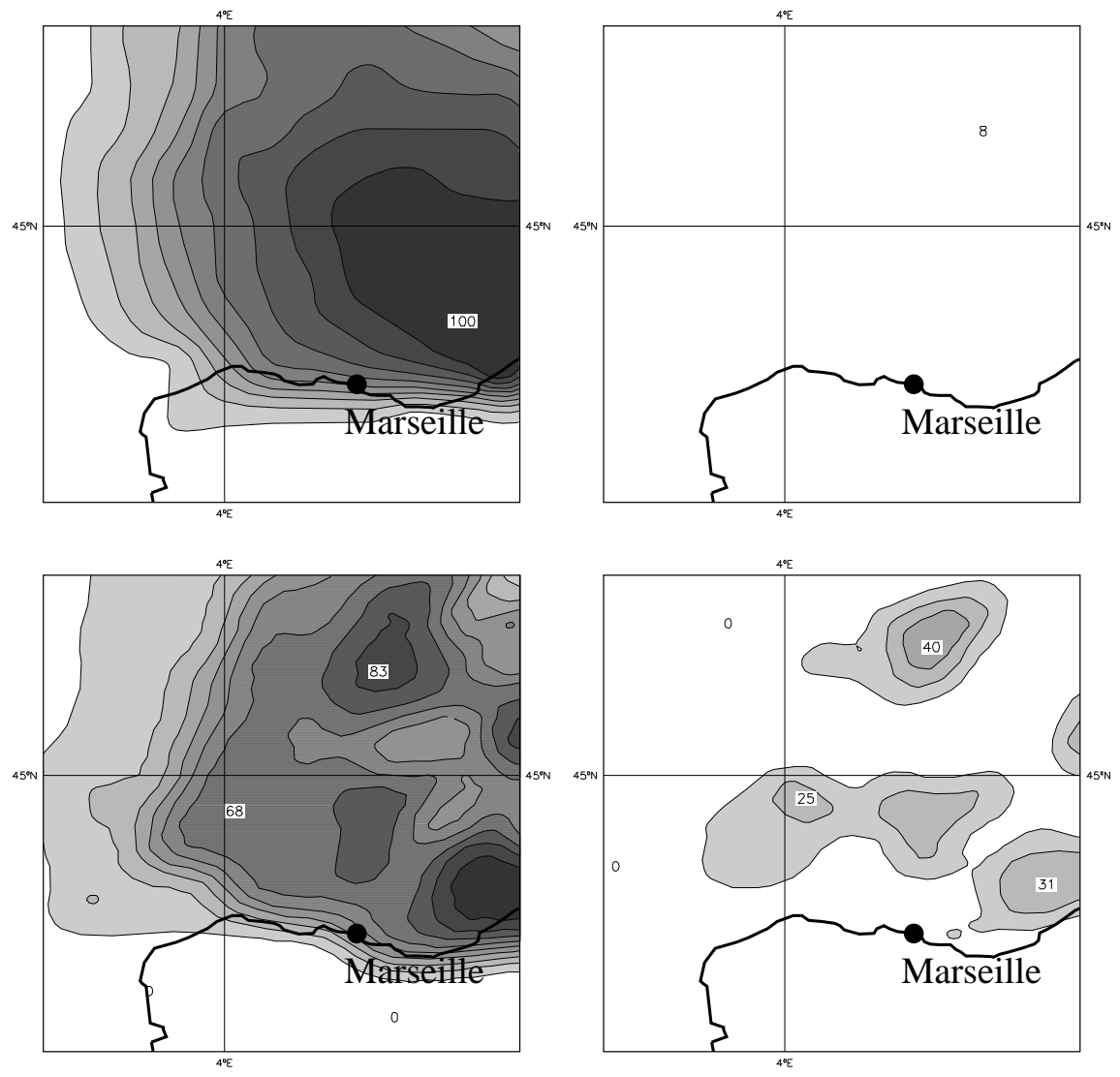

Fig. 3. Vaison flood. 3-day predictions: TEPS (top row) and LEPS (bottom row) rainfall probability maps valid at 6:00 UTC on 23 September 1992 (cumulated between forecasts $t+42 \mathrm{~h}$ and $t+66 \mathrm{~h}$ ) for rainfall exceeding 20 (left column) and 50 (right column) $\mathrm{mm} /$ day. Contours are located at every $10 \%$. improves, as shown in Fig. 3. The left column panels of the figure show a very high probability of rainfall exceeding $20 \mathrm{~mm} /$ day over a broad region between southern France and Italy, including the area of the flood. Nevertheless, none of the ECMWF ensemble members predicts rainfall rates exceeding $50 \mathrm{~mm} /$ day over the region affected by the flood; therefore, the top right panel of the figure does not show any indication of possible heavy rain in the Vaison area. On the other hand, the bottom right panel shows that the $72 \mathrm{~h}$ LEPS forecasts indicate a $25 \%$ probability of heavy rainfall (above $50 \mathrm{~mm}$ ) over a region which includes Vaison. In addition to this, the bottom row panels provide more detailed precipitation patterns in comparison with the TEPS probability maps. The Z700 forecasts indicate that the geopotential height patterns predicted by some TEPS members are close to the verification patterns (not shown), although several ECMWF runs predict the location of the low-level trough too far to the east in comparison with the analysis. Table 2 shows that the lowest Z700 prediction errors are obtained by the RMs of the two most populated clusters (1st and 3rd ones), which are representative of the most likely evolution scenarios.

Therefore, though the TEPS probability maps are of greater assistance than in the previous case, they still do not indicate a clear probability of the rainfall rate exceeding $50 \mathrm{~mm} /$ day. On the other hand, LEPS runs are more accurate and the probability maps provide enough information to suggest heavy rain as a possible scenario ( $25 \%$ of probabil- ity), thus giving a hypothetical forecaster the possibility to issue a warning three days before the weather event hits the region.

\subsection{Two-day forecast}

As the forecast range shortens to 2 days, the prediction accuracy increases further. In the TEPS runs, the cluster analysis indicates that the most likely evolution scenario is provided by the first cluster (see Table 1) and that the control forecast is the RM of this cluster (the most populated one with 25 members). In addition to this, the $\mathrm{Z} 700$ prediction errors of 4 out of $5 \mathrm{RMs}$ are lower than in the previous cases (according to Table 2), suggesting an improved performance of the ECMWF TEPS for this range. In the top left panel of Fig. 4, the rainfall probability map obtained by the TEPS integrations indicate a high probability of rainfall exceeding $20 \mathrm{~mm} /$ day over a broad region, with two peaks in probability (about 100\%) over southern France and northwestern Italy. As in the previous case, the probability of the rainfall rate exceeding the $50 \mathrm{~mm} /$ day threshold is below $10 \%$ in the region affected by the flood (top right panel of the figure). On the other hand, LEPS integrations predict heavy rainfall scenarios in the correct region. The bottom row panels of Fig. 4 show that the probability maps at high-resolution indicate for the lower threshold a rainfall pattern with more details as compared to that obtained by the ECMWF integra- 

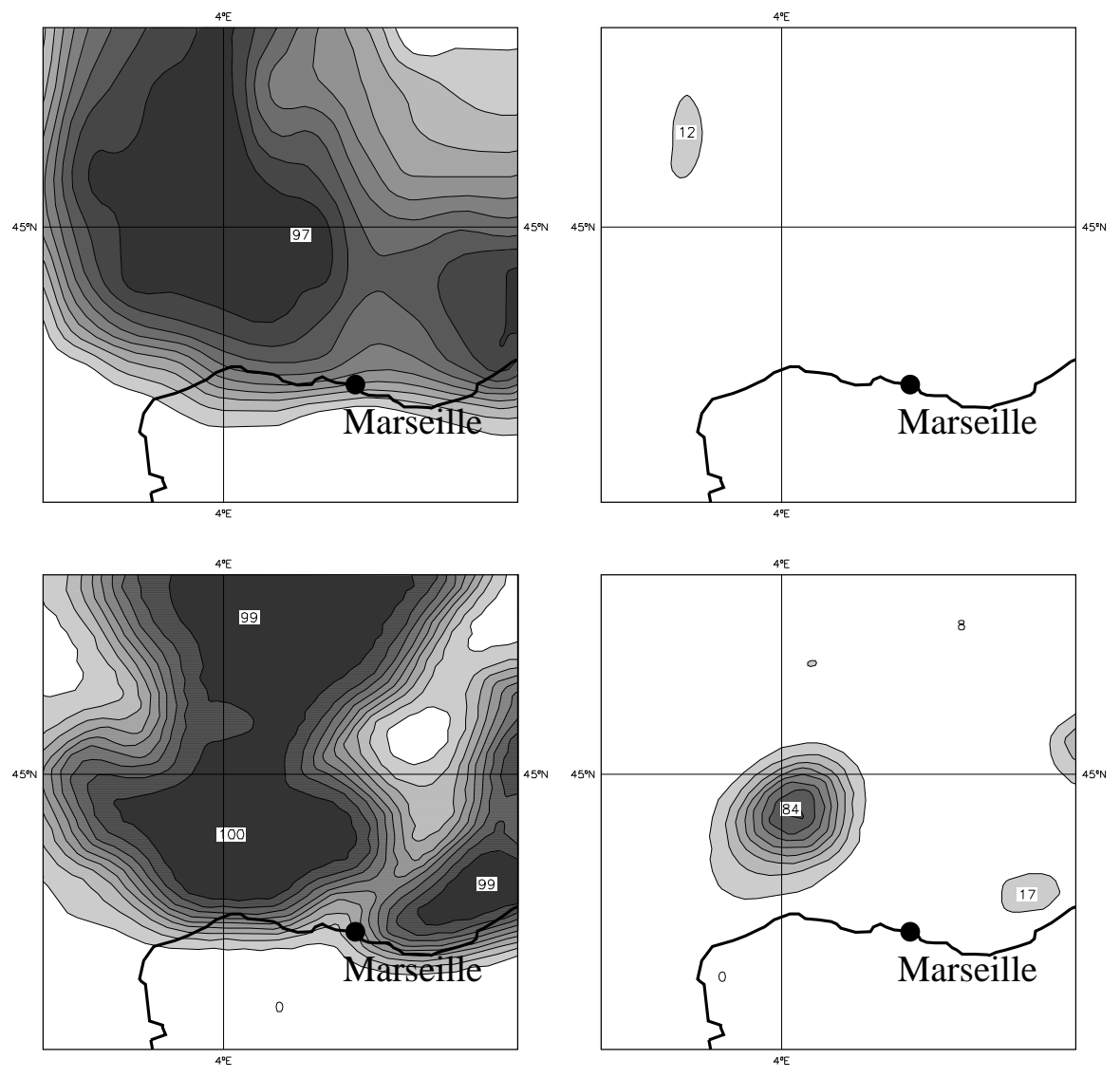

Fig. 4. Vaison flood. 2-day predictions: the same as Fig. 3, but for rainfall cumulated between $t+18 \mathrm{~h}$ and $t+42 \mathrm{~h}$. tions; this reflects, among other factors, a better description of orography. The bottom right panel of the figure confirms the likelihood of extreme rainfall, already highlighted by the $72 \mathrm{~h}$ runs, with an $84 \%$ maximum of probability for precipitation exceeding $50 \mathrm{~mm} /$ day. In particular, the probability pattern clearly shows the main peak at about $45^{\circ} \mathrm{N} 4^{\circ} \mathrm{E}$, very close to the actual location of the flood. As these very high values suggest a clear chance of a flood, they could assist the forecaster in issuing a warning, thereby alerting civil protection agencies two days before the event. These results confirm the limitation of the TEPS' ability to predict heavy precipitation. Nevertheless, it should be also noted that the resolution of the TEPS members ( $T_{L} 159$ corresponding to about $120 \mathrm{~km}$ in grid-point space) may not be sufficient enough to properly describe those orographic effects that play a crucial role in determining the conditions for heavy precipitation in this case study. This is underlined by the different probability patterns obtained by the TEPS and LEPS in the $20 \mathrm{~mm}$ threshold (left column panels of Fig. 4). One notices that the TEPS maps cannot resolve the narrow strip of heavy precipitation over the Liguria coast (northwestern Italy), highlighted, on the other hand, by the LEPS runs and confirmed by the observations. Therefore, while in the TEPS probability maps the signal for heavy precipitation is still weak, the information provided by the LEPS runs is much more accurate and realistic, thereby predicting with high spatial detail the regions most affected by the weather event.

\subsection{Higher resolution run}

Once a flood scenario over a region is predicted with a high probability of occurrence (as in the $48 \mathrm{~h}$ LEPS runs), it is of crucial importance to have a very detailed description of the precipitation pattern within the region itself. Hence, it can be necessary to further augment the resolution of the limitedarea model in order to have an enhanced description of the orography and the related physical processes. This may help to provide a more reliable quantitative estimate of the total amount of rainfall which is about to fall over the region. In order to address this point, one further run was performed at a higher horizontal resolution (5 instead of $20 \mathrm{~km}$, still with 32 vertical levels), nested on that $48 \mathrm{~h}$ LAMBO run relative to the RM of the most populated cluster (the first one with 25 members, according to Table 1). Due to the limitations in the computer power, the domain of integration was kept smaller than in the previous integrations and centered approximately over the region affected by the flood ${ }^{1}$.

Figure 5 shows the precipitation pattern predicted by this high-resolution run over its domain. This LAMBO integra-

\footnotetext{
${ }^{1}$ It is also worth noting that the deterministic higher resolution approach is prohibitive for ARPA-SMR computing facilities with forecast ranges exceeding $48 \mathrm{~h}$
} 


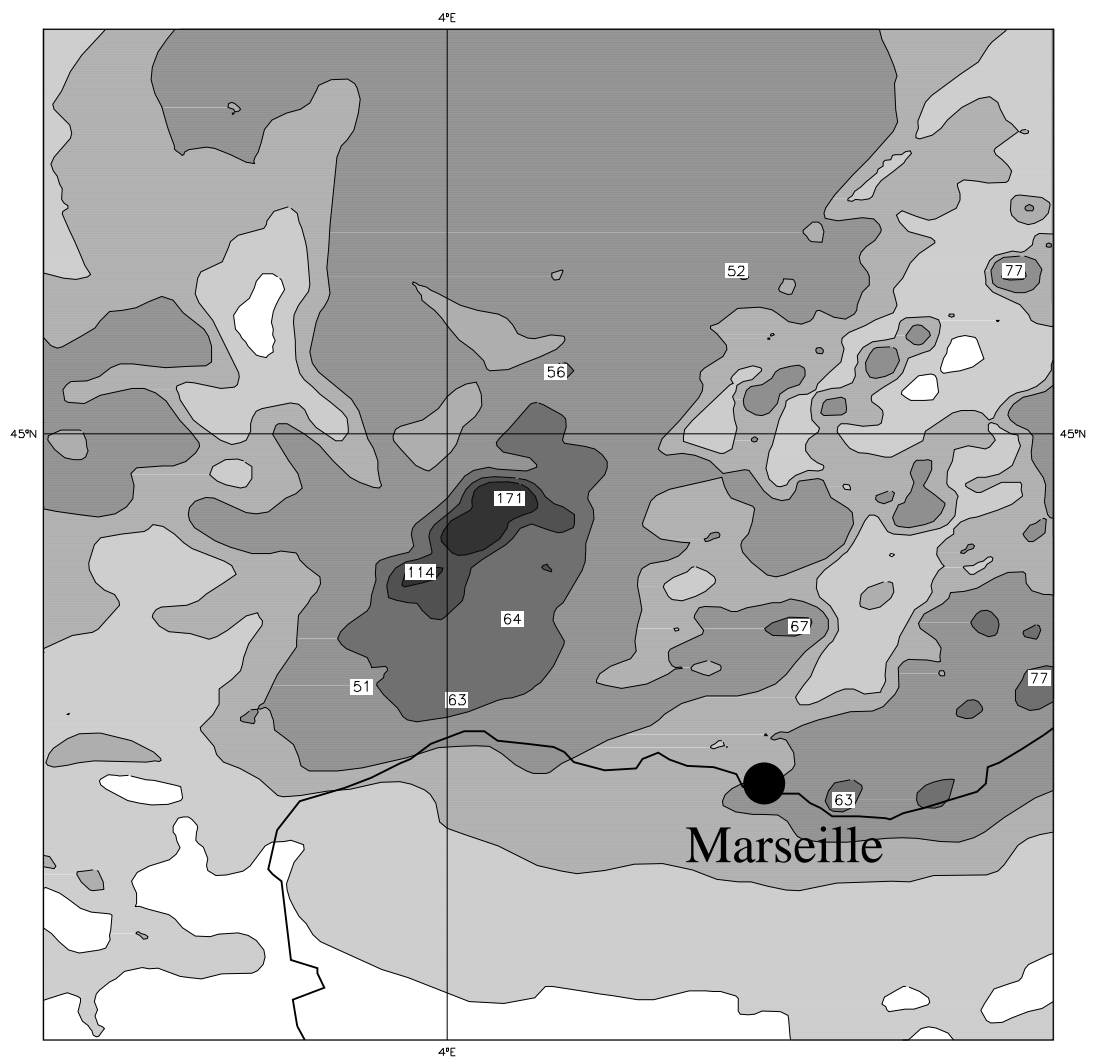

Fig. 5. Vaison flood. Total precipitation cumulated between $t+18$ and $t+42 \mathrm{~h}$ predicted by LAMBO ("higherresolution" configuration), starting at 12:00 UTC on 21 September 1992. Contour intervals: $2,10,50,75,100$, 150 and $200 \mathrm{~mm}$.

tion is very accurate in terms of total precipitation: it predicts a rainfall maximum of about $170 \mathrm{~mm}$ in an area very close to that which was actually flooded, where the maximum observed value was $159 \mathrm{~mm}$. In addition to this, the amounts of rainfall predicted along the coast are quite close to those observed and reported in Fig. 1. The predictions of other fields (not shown), such as Z700 or mean sea level pressure, are also quite accurate, indicating the benefits gained by an enhancement of horizontal resolution for the prediction of a low-level meteorological field.

\section{Genova case}

The results obtained by the TEPS and LEPS integrations for the Genova flood are partly different from those described in the previous section for the Vaison case. The TEPS performance is much more accurate than in the previous case at any range and this reduces the amount of information gained when the limited-area ensemble is considered. Hence, the better performance of the LEPS runs is less evident than before. In the following, the attention is focussed on the 4-day and 2-day forecasts (3-day forecasts are not shown, since the results are almost identical to those obtained for the 2-day range), as well as on the higher resolution run.

\subsection{Four-day forecast}

At the longest forecast range, both the global and, to a lesser extent, the limited-area ensembles misplace the location of the region affected by heavy rain. The amount of precipitation is underestimated over the Liguria region and over-estimated over southern France. The left panel of Fig. 6 shows the TEPS probability map for rainfall exceeding $20 \mathrm{~mm} /$ day, representing a broad region with high probability of precipitation ranges from $4^{\circ} \mathrm{E}$ to $9^{\circ} \mathrm{E}$, with a $85 \%$ maximum near the French-Italian border. The right panel of Fig. 6 shows the more detailed rainfall pattern of the LEPS integrations, which predict the high possibility of precipitation exceeding $20 \mathrm{~mm} /$ day all along the coast and not only to the west of $9^{\circ} \mathrm{E}$. A probability peak of $81 \%$ is well evident just over the town of Genova, although rainfall exceeding $20 \mathrm{~mm} /$ day is expected almost everywhere in northwestern Italy. At the $50 \mathrm{~mm} /$ day threshold, not a single run by either TEPS or LEPS predicts heavy rainfall in northwestern Italy, but rather over southern France (where heavy rain was not actually observed) and the probability maps for rainfall exceeding this threshold are not shown. In particular, the LEPS performance at the $50 \mathrm{~mm} /$ day threshold is quite poor: a $70 \%$ probability maximum is located at about $44^{\circ} \mathrm{N} 4^{\circ} \mathrm{E}$, completely misplaced in comparison to the actual flood location, and there is no indication of the possibility of a flood over the Liguria region.

Therefore, at the longest forecast range, both the TEPS 

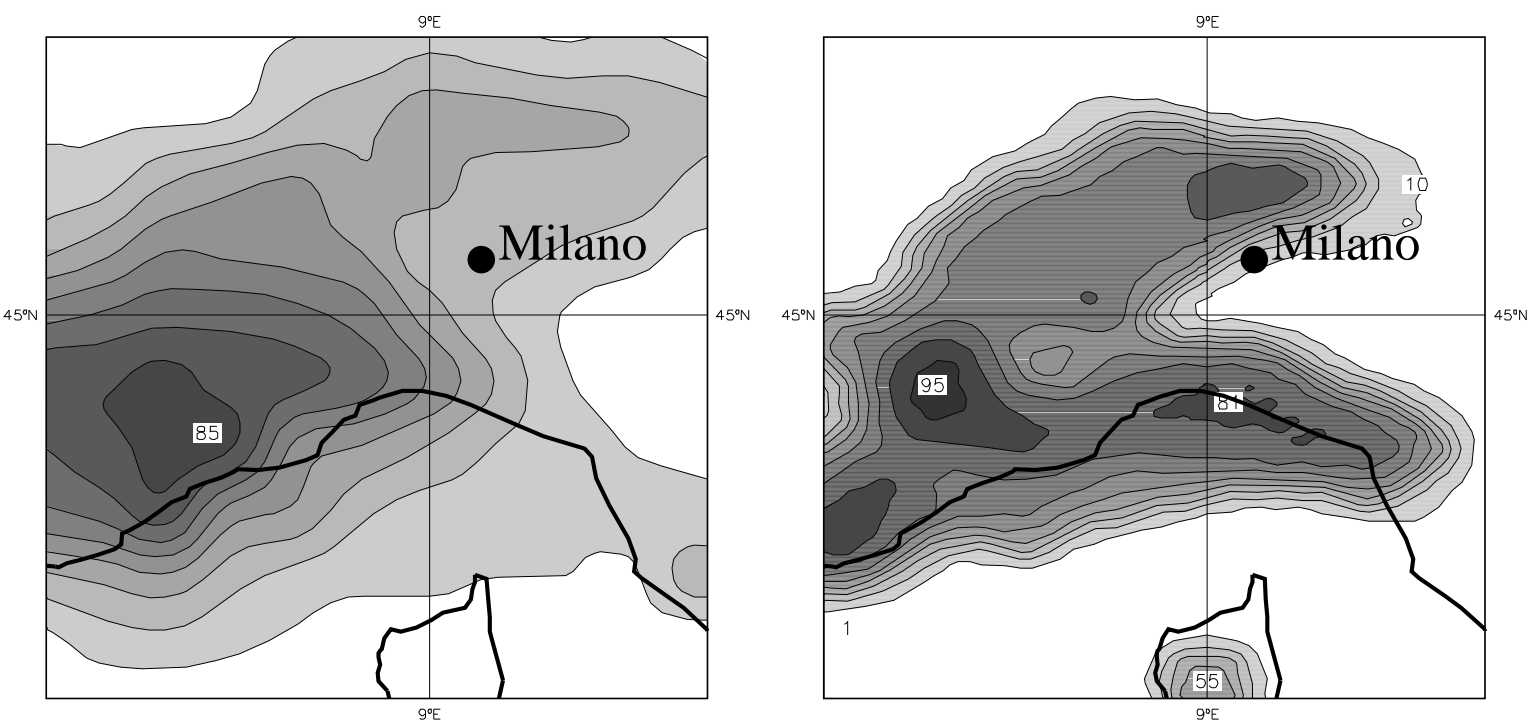

Fig. 6. Genova flood. 4-day predictions: TEPS (left panel) and LEPS (right panel) rainfall probability maps valid at 12:00 UTC on 28 September 1992 (cumulated between $t+72 \mathrm{~h}$ and $t+96 \mathrm{~h}$ ) for rainfall exceeding $20 \mathrm{~mm} /$ day. Contours are located at every $10 \%$.

and LEPS maps indicate the possibility of rainfall over the region of Genova, although the intensity of the event is not properly captured at this stage.

\subsection{Two-day forecast}

At the shorter prediction ranges, the accuracy of both global and limited-area ensemble forecasts increases. Figure 7 shows the performance of TEPS and LEPS for the 2-day forecast range (top row and bottom row panels, respectively). One notices that the global model predicts the high possibility of rainfall too far to the west, when compared to the observations in the bottom right panel of Fig. 1. In fact, at the lower threshold, there is a very broad probability maximum covering the northwestern coast for almost $500 \mathrm{~km}$ (top left panel), while the probability of rainfall exceeding $50 \mathrm{~mm} /$ day shows a more localised peak, with a $76 \%$ maximum at about $43^{\circ} \mathrm{N} 6^{\circ} \mathrm{E}$ (top right panel). The LEPS performance is similar to that obtained by the TEPS, at least for the geographical location of the regions affected by heavy precipitation, since the westward displacement is evident but to a lesser extent also in the LAMBO integrations. The bottom left panel of Fig. 7 shows a probability maxima over northwestern Italy and southern France, while at the $50 \mathrm{~mm} /$ day threshold, a broad peak in the rainfall probability is evident all along the coast to the west of Genova (bottom right panel).

Therefore, in the LEPS maps, the probability of heavy rainfall is always higher than in the ECMWF runs, with the horizontal details also more accurate than in the global runs. Nevertheless, both ensembles predict a rainfall pattern slightly misplaced to the west when compared to the observations.

\subsection{Higher resolution run}

As in the previous case, a further $48 \mathrm{~h}$ LAMBO run was performed in the higher resolution configuration $(5 \mathrm{~km}$ of horizontal resolution) to obtain a more detailed quantitative rainfall estimate over the flooded region. Figure 8 shows the results obtained by the higher resolution integration nested on the RM of the first cluster, which is the most populated one with 29 members, as in Table 1 . The rainfall forecast indicates the heaviest precipitation rates over the coast to the west of Genova, with peaks above $180 \mathrm{~mm} / \mathrm{day}$, and a secondary maximum also evident along the western Alps, at about $45^{\circ} \mathrm{N} 7^{\circ} \mathrm{E}$. A direct comparison with the observations in the bottom right panel of Fig. 1 shows that although this run properly forecasts heavier precipitation over the western rather than the eastern coast, the rainfall maxima are still located too far to the west. In fact, the $300 \mathrm{~mm}$ peak over the town of Genova is missing and the Z700 forecast (not shown) indicates the small-scale trough slightly misplaced to the west (in comparison with its actual position). Nevertheless, both the intensity and the timing of the weather event are well captured, thereby enabling a forecaster to alert, those organizations involved in public security, as well as the local population two days before the event.

\section{Conclusions}

The performance of LEPS, the ARPA-SMR limited-area ensemble prediction system nested in the experimental TEPS, was tested, thereby investigating the predictability of two flood weather events for the forecast times ranging between 2 and 4 days. LEPS is composed of five runs of the highresolution limited-area model LAMBO, nested on five selected members of the ECMWF TEPS, the recently devel- 

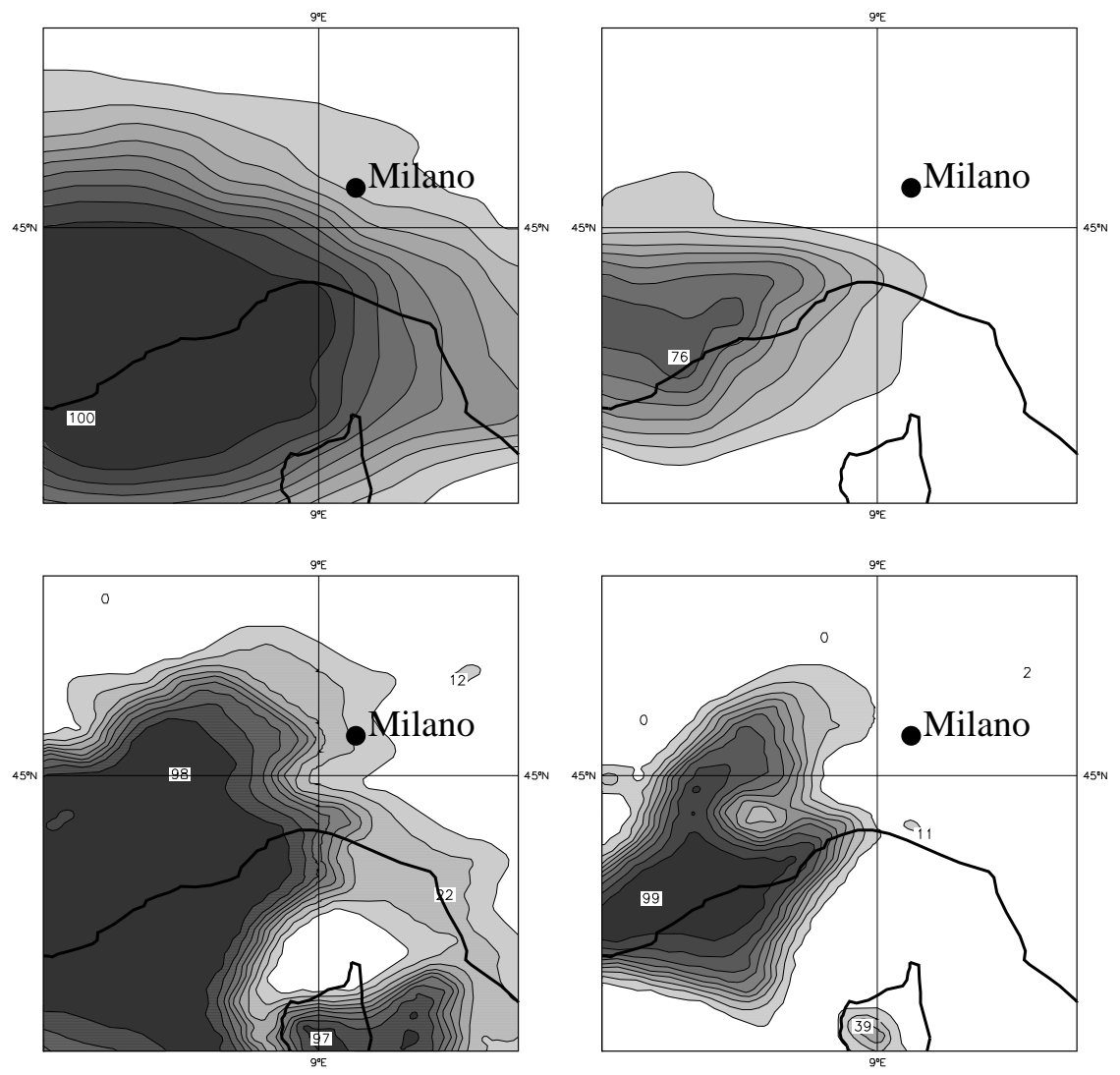

Fig. 7. Genova flood. 2-day predictions: TEPS (top row) and LEPS (bottom row) rainfall probability maps valid at 12:00 UTC on 28 September 1992 (cumulated between $t+24 \mathrm{~h}$ and $t+$ $48 \mathrm{~h}$ ) for rainfall exceeding 20 (left column) and 50 (right column) $\mathrm{mm} /$ day. Contours are located at every $10 \%$. oped targeted global ensemble, where the initial perturbations maximise their $48 \mathrm{~h}$ growth over the European area. A combination of four variables at four pressure levels (from $500 \mathrm{hPa}$ downwards) is used to discriminate among members. This selection technique enables one to identify those TEPS members which show some similarity throughout the mid to lower troposphere in terms of both the dynamical and humidity components. More precisely, a clustering technique is first applied in order to group the members into five clusters and then to select a representative member (RM) from each cluster. The selected RMs provide the boundary and initial conditions for the five LAMBO runs, each of them representative of a possible weather evolution scenario. Probability maps obtained by both TEPS and LEPS were prepared for rainfall rates exceeding two different thresholds (20 and $50 \mathrm{~mm} /$ day).

For the Vaison case, at the forecast ranges of $t+72 \mathrm{~h}$ and $t+48 \mathrm{~h}$, the comparison indicates a better performance of LEPS with regard to both the spatio-temporal prediction of the event and its intensity. As the forecast range decreases, both the TEPS and LEPS configurations indicate a higher and higher probability of rainfall in the correct region, although the information provided by LEPS still looks more reliable. The flood evolution is more accurately predicted in the LEPS runs, especially for high precipitation thresholds. At the shortest range, in addition to the probabilistic approach, one higher resolution $(5 \mathrm{~km}$ in the horizon- tal) LAMBO run was performed, nested on the most likely weather evolution scenario highlighted by the cluster analysis on the ECMWF TEPS. The high-resolution run shows an enhanced description of the rainfall pattern, thereby providing an accurate quantitative rainfall pattern in approximately the correct location.

For the Genova case, the impact is less evident, as the TEPS predictions are more accurate than for the Vaison case. At day 4, the LEPS runs are still slightly more accurate in the detection of the regions affected by precipitation, although the intensity of the weather event is underevaluated by both the TEPS and LEPS integrations. At the shorter ranges, both TEPS and LEPS suggest a high probability of heavy precipitation over northwestern Italy, with the rainfall maxima always located too far to the west. In addition, in this case, the LEPS probability maps always indicate higher probability values, especially for high rainfall thresholds. When LAMBO is run in the higher resolution configuration, the precipitation pattern is very detailed and quite accurate, although the rainfall maxima are still displaced to the west.

The experiments of this study confirm the validity of the LEPS system with regard to the spatio-temporal prediction of the regions affected by heavy precipitation. The results do represent a step forward in the direction of improving the probability forecasts of localised and extreme weather events for different forecast ranges, thanks to the more detailed description of orographic and mesoscale processes, which are 


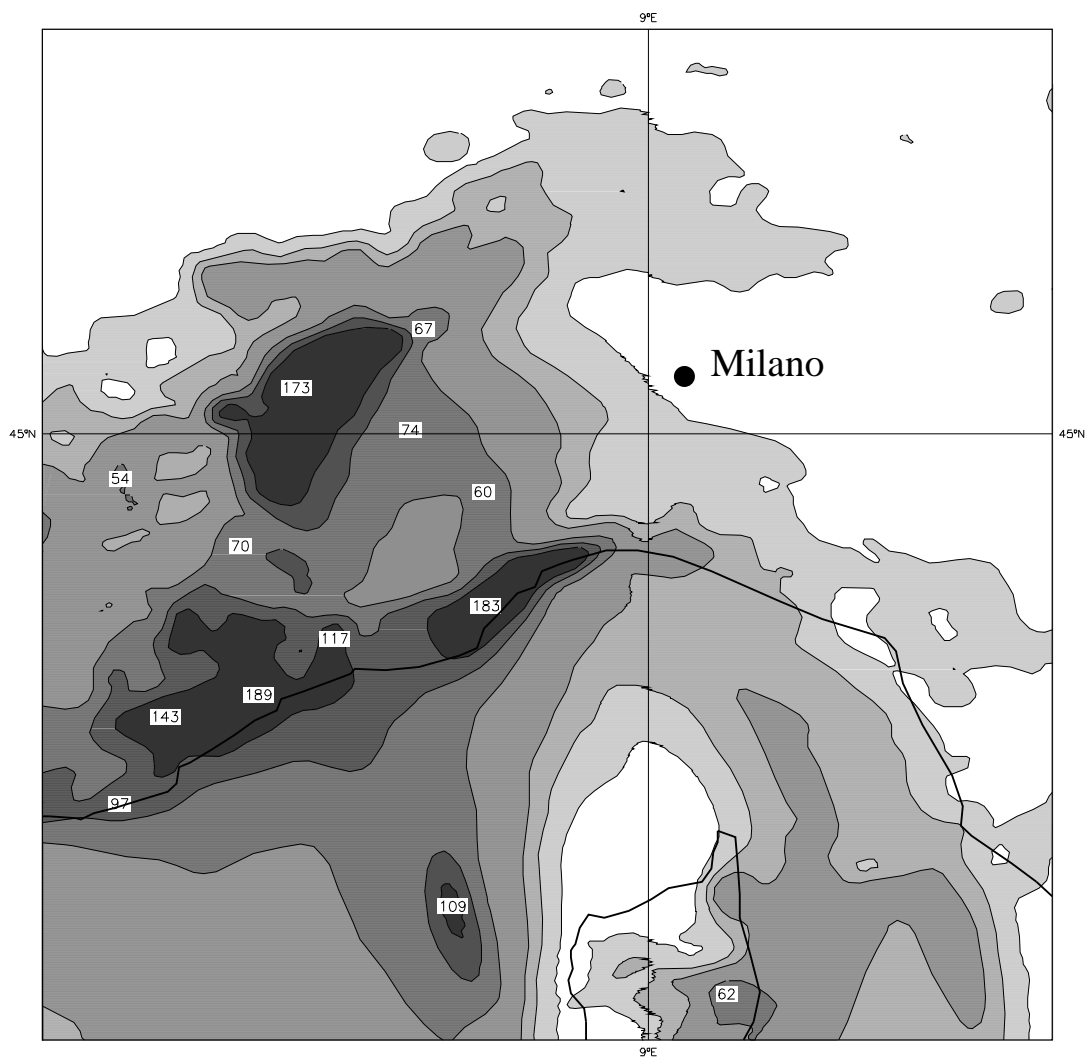

Fig. 8. Genova flood. Total precipitation cumulated between $t+24 \mathrm{~h}$ and $t+48 \mathrm{~h}$ predicted by LAMBO ("higher resolution" configuration), starting at 12:00 UTC on 26 September 1992. Contour intervals: 2, 10, 50, 75, 100, 150 and $200 \mathrm{~mm}$.

better resolved in the high-resolution model. In particular, the forecasts provided by the higher resolution runs seem to answer the three crucial questions (timing, location and intensity of precipitation) involved in the prediction of rainfall. Nevertheless, the high-resolution configuration is extremely expensive from a computation point of view, thereby making its operational use very difficult with the present computing facilities. Since only two flood cases were investigated, it is not yet possible to draw any general conclusion on the relative performance of TEPS and LEPS in the case of heavy precipitation. Therefore, a systematic study was undertaken by running TEPS twice a week and considering the performance of the configuration TEPS-LEPS for a longer time period in order to obtain more robust statistical results. As already mentioned, the TEPS experimentation started in January 1999 as a special project at ECMWF and the performance of the TEPS-LEPS configuration during this year will be fully addressed in forthcoming studies.

Acknowledgements. The authors thank Davide Cesari, Federico Grazzini, Hans Hersbach and Stefano Tibaldi for useful discussions and Paolo Patruno for technical assistance. This work was sponsored by a grant from GNDCI-CNR (Gruppo Nazionale Difesa Catastrofi Idrogeologiche - Consiglio Nazionale delle Ricerche) and from CIMA (Centro di ricerca In Monitoraggio Ambientale) on funds of the European program INTERREG II C. Andrea Montani was supported during part of this study by a Icarus studentship at CINECA, Italy.

\section{References}

Atger, F.,: The Skill of Ensemble Prediction System, Mon. Weather Rev., 127, 1941-1953, 1999.

Buizza, R. and Palmer, T. N.: The singular-vector structure of the atmospheric global circulation, J. Atmos. Sci., 52, 1434-1456, 1995.

Buizza, R., Petroliagis, T., Palmer, T. N., Barkmeijer, J., Hamrud, M., Hollingsworth, A., Simmons, A., and Wedi, N.: Impact of model resolution and ensemble size on the performance of an ensemble prediction system, Quart. J. Roy. Meteor. Soc., 124, 1935-1960, 1998.

Hersbach, H., Mureau, R., Opsteegh, J. D., and Barkmeijer, I.: A short-range to early-medium-range Ensemble Prediction System for the European Area, Mon. Weather Rev., 128, 3501-3519, 2000.

Houtemaker, P. L., Derome, J., Ritchie, H., and Mitchell, H. L.: A systematic simulation approach to ensemble prediction, Mon. Weather Rev., 124, 1225-1242, 1996.

Janjic, J.: The step-mountain coordinate: physical package, Mon. Weather Rev., 118, 1429-1443, 1990.

Marsigli, C., Montani, A., Nerozzi, F., Paccagnella, T., Tibaldi, S., Molteni, F., and Buizza, R.: A strategy for high-resolution ensemble prediction. Part II: limited-area experiments in four Alpine flood events, Accepted at Quart. J. Roy. Meteor. Soc., 2001.

Molteni, F., Buizza, R., Palmer, T. N., and Petroliagis, T.: The ECMWF Ensemble Prediction System: Methodology and validation, Quart. J. Roy. Meteor. Soc., 122, 73-119, 1996.

Molteni, F., Buizza, R., Marsigli, C., Montani, A., Nerozzi, F., and 
Paccagnella, T.: A strategy for high-resolution ensemble prediction. Part I: definition of representative members and globalmodel experiments, Accepted at Quart. J. Roy. Meteor. Soc., 2001.

Palmer, T. N., Gelaro, R., Barkmeijer, J., and Buizza, R.: Singular vectors, metrics and adaptive observations, J. Atmos. Sci., 55, 633-653, 1998.

Senesi, S., Bougeault, P., Cheze, J. L., Cosentino, P., and Thepenier, R. M.: The Vaison-la-Romaine Flash Flood: Meso-Scale Analysis and Predictability Issues, Metèo France, CNRM, Note du GMME no 35, 60 pp., 1996.

Stensrud, D. J., Bao, J.-W., and Warner, T. T.: Using initial conditions and model physics perturbations in short-range ensembles. Part I: ensemble description and precipitation verification, Submitted to Mon. Weather Rev., 1999a.
Stensrud, D. J., Bao, J.-W., and Warner, T. T.: Using initial conditions and model physics perturbations in short-range ensembles. Part II: error growth and creation of variance, Submitted to Mon. Weather Rev., 1999b.

Toth, Z. and Kalnay, E.: Ensemble forecasting at NMC: the generation of perturbations, Bull. Am. Met. Soc., 125, 2317-2330, 1993.

Tracton, M. S., Du, J., Toth, Z., and Juang, H.: Short-range ensemble forecasting (SREF) at NCEP/EMC, Proceedings of the 12th AMS/NWP Conference, Phoenix AZ, 269-272, 1998.

Wilks, D. S.: Statistical atmospheric sciences, Academic Press, San Diego, CA, USA, 1995.

Ziehmann, C.: Comparison of a single-model EPS with a multimodel ensemble consisting of a few operational models, Tellus, 52A, 280-299, 2000. 